\section{A random-pulse generator with adjustable pulse duration}

\author{
JOSEPH SIA
}

Research Division, Neuropharmacology Section

Hoffmann-LaRoche, Inc., Nutley, New Jersey 07110

An electronic device for generating random pulses of adjustable duration within a minimal and maximal interval boundary is described. The instrument is useful in electro- and psychophysiological research where randomization of stimulus input is required.

In many electro- and psychophysiological experiments, repetitive stimulation at fixed intervals evokes responses which change with each subsequent stimulus for many different reasons, e.g., recovery cycle, habituation, expectancy. It is, therefore, desirable to deliver controlled stimuli at random within a specified interval boundary. This also reduces the contamination of sampled data with a regularly occurring interference signal. The following is a description of a compact device, which avoids the use of expensive digital computer techniques and multiple instrumentation as described recently (Rovner \& Walter, 1970).

Figure 1 represents the circuit diagram of the instrument. A zener diode (Type IN 1770) with a high noise level output of between 2 and $5 \mathrm{mV}$ peak-to-peak was chosen as frequency generator. After eliminating some of the high-frequency components by .22- and .47-microF capacitors, the signal was amplified by Amplifiers A1 and A2 (Type 741). The ac component present at the output of Amplifier A2 was subsequently applied to another operational amplifier, A3, of the same type. The input to this third amplifier was controlled by two diodes $\left(D_{3}\right.$, $\mathrm{D}_{4}$ ), in order to determine the minimum and maximum boundary of the output signal. The output obtained at $D$ is a dc level, randomly changing approximately between +10 and $+20 \mathrm{~V}$ in reference to $-15 \mathrm{~V}$ (Fig. 2). This voltage is applied through a resistance RJ to a U.J.T. relaxation oscillator circuit. The time (T) for the capacitor (C) to charge to the voltage $\left(V_{P}\right)$ which operates the U.J.T. is:

$$
T=R C \ln \frac{V_{E}}{V_{E}-V_{P}}
$$

where $V_{P}$ is the peak point voltage at which the unijunction operates and $V_{E}$ is the source voltage to the $R C$ circuit. The frequency of the oscillator is dependent on the stability of RC, $V_{E}$, and of the U.J.T. Since RC is constant, an incremental change of $V_{E}$ produces an incremental change in the time base

$$
\Delta T=-\Delta V_{E} \frac{V_{P} R_{C}}{V_{E}\left(V_{E}-V_{P}\right)}
$$

If the minimum and maximum $\mathrm{V}_{\mathrm{E}}$ is known, the interval boundary, $T$ (Fig. 2), may be determined. Changing the value of $\mathrm{RJ}$ sets new frequency boundaries. With $\mathrm{SW}_{1}$ in Position 1, the minimal and maximal $T$ is 1.3 and 1.5 sec, respectively; in Position 2, T $\min$ is $0.8 \mathrm{sec}$ and $\mathrm{T} \max$ is $1.3 \mathrm{sec}$; in Position $3, \mathrm{~T}$ min is $0.4 \mathrm{sec}$ and $\mathrm{T} \max$ is 1.2 sec.

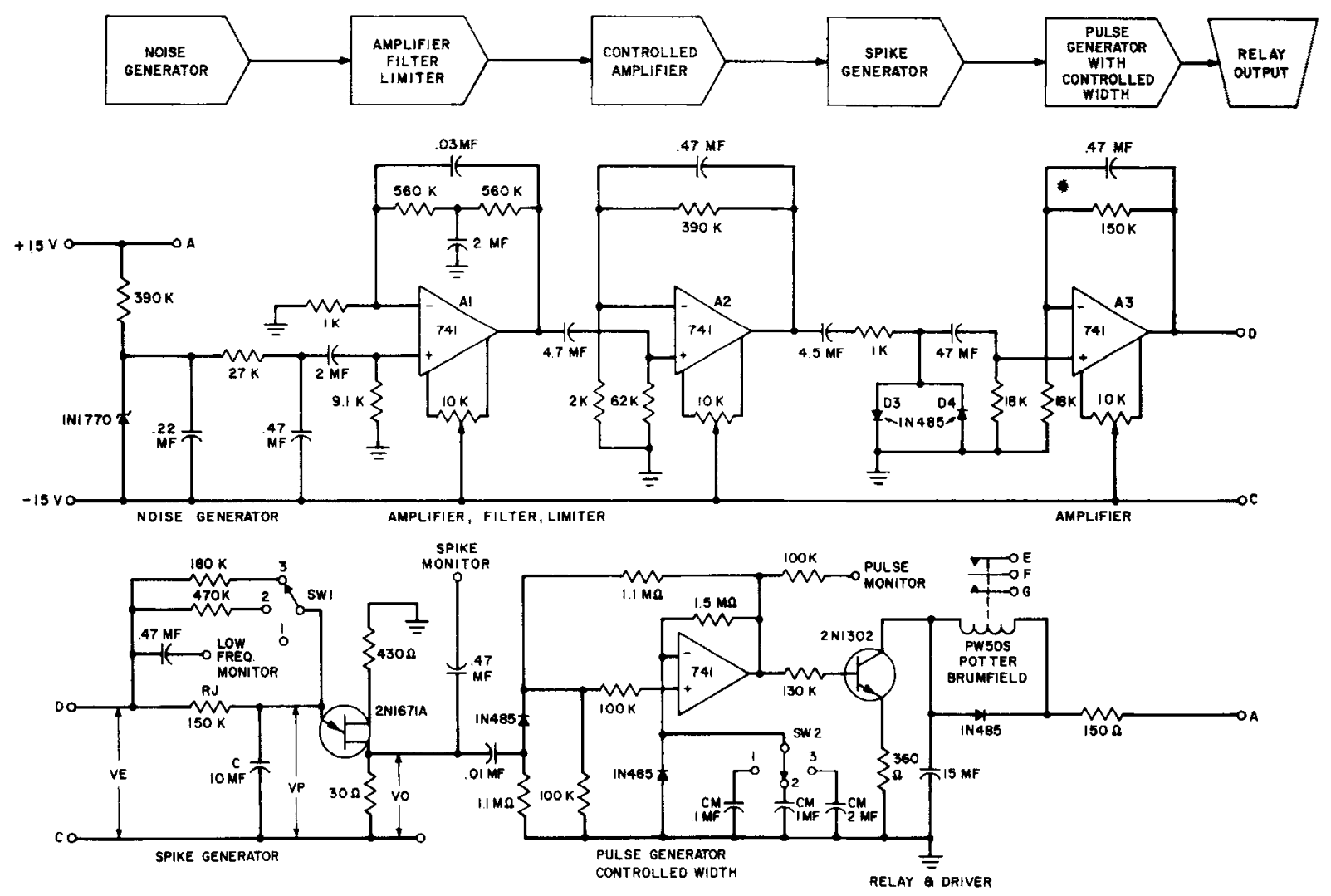

Fig. 1. Circuit diagram of random-pulse generator with adjustable pulse duration. 
Resistors (carbon, $1 / 4$ watts, $5 \%$ or $10 \%$ tolerance) $26 @ \$ .09$

$2390 \mathrm{k} \Omega$ value

$127 \mathrm{k} \Omega$

$21 \mathrm{~K} \Omega$

$19.1 \mathrm{k} \Omega$

$2560 \mathrm{~K} \Omega$

$12 \mathrm{k} \Omega$

$162 \mathrm{k} \Omega$

$218 \mathrm{~K} \Omega$

$2150 \mathrm{~K} \Omega$

$1180 \mathrm{k} \Omega$

$1470 \mathrm{k} \Omega$

$1430 \Omega$

$130 \Omega$

$21.1 \mathrm{M} \Omega$

$2100 \mathrm{k} \Omega$

$11.5 \mathrm{M} \Omega$

$1130 \mathrm{~K} \Omega$

$1360 \Omega$

$1150 \Omega$

2 3-position rotary switches (on-off switch) No. 1461 Centralab 1 PW5DS Potter-Brumfield relay

$310-\mathrm{K} \Omega$ series 3800 micropot trimmers, or equivalent (Allied)

3 BNC bulkhead receptacles, Amphenol No. UG-1094/U-1050

3 Binding posts, Grayhill or equivalent, Type 29-1 or $29-3$

1 Power line cord ( 3 conductor)

1 Cabinet, Vector No. W 45-86-46

Solid-State Devices

$4 \mu \mathrm{A} 741$ operational amplifiers

$12 \mathrm{~N} 1671 \mathrm{~A}$ unijunction transistor

$12 \mathrm{~N} 1302$ transistor

5 IN 1770 zener diodes (choose the one with the greater noise level)

5 IN 485 general purpose diodes

1 Power supply \pm 15 VDC Model DCP-15K (\$45-\$50)

Condensers (working voltage not less than $50 \mathrm{~V}$ ) Supplier: Allied $12 @ \$ .75$ and $6 @ \$ 1.50$ (total $\$ 18$ )

$10.22 \mu \mathrm{F}, 50.47 \mu \mathrm{F}, 10.03 \mu \mathrm{F}, 14.7 \mu \mathrm{F}$

$14.5 \mu \mathrm{F}, 147 \mu \mathrm{F}, 110 \mu \mathrm{F}, 10.01 \mu \mathrm{F}$

$10.1 \mu F$ mylar cond., $11 \mu F, 12 \mu F$ (italicized are all mylar)

$22 \mu F$ mylar cond., $115 \mu F$

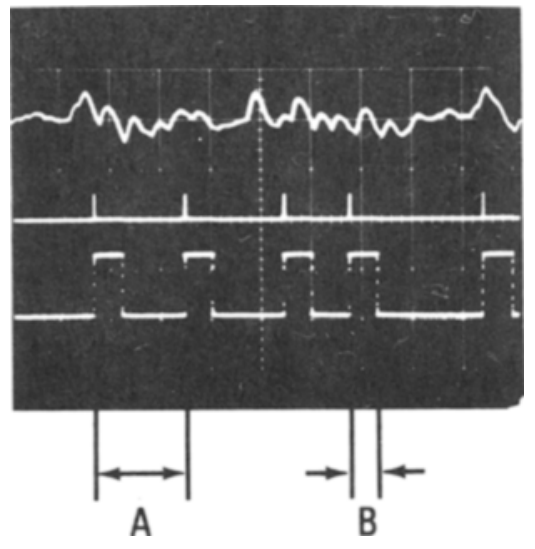

The output $V_{O}$ of the U.J.T. is applied to a 741 operational amplifier used in a monostable multivibrator circuit configuration. The value of $\mathrm{CM}$ in the multivibrator circuit determines the pulse duration (Fig. 2). In the schematic, with the values of the three

Fig. 2. Output obtained at various stages of the random-pulse generator. Upper trace: DC level as measured at $D$ of the circuit diagram in Fig. 1. Middle trace: Pulses determining the interval boundary (T). Lower trace: Determination of pulse duration by value of $C M$ in multivibrator circuit. A: Variable interval boundary. B: Pulse duration.
Suggested Supplier

Allied Electronics Corp.

Valley Stream, N.Y. 11580

or

2400 W. Washington Blvd.

Chicago, Ill. 60680 \begin{tabular}{l} 
Supplier \\
\hline Allied \\
Allied \\
Allied \\
Allied \\
Allied \\
Allied \\
Allied
\end{tabular}

Manufacturer

Fairchild

Fairchild

Texas Instruments

International Rectifier Semiconductors

Texas Instruments

Power Mate Corp., Hackensack, N.J.

Sprague

Sprague

TRW

TRW capacitors $\mathrm{CM}$ present, the pulse durations available are 0.04 (No. 1), 0.3 (No. 2), and 0.4 (No. 3) sec, respectively. The multivibrator output is fed into a transistor which operates a relay that closes and opens a circuit applied to E-F or G-F.

The approximate price of the unit is $\$ 140-\$ 150$. The parts list is presented in Table 1 .

\section{REFERENCE}

ROVNER, L., \& WALTER, D. O. An adjustable random-pulse generator. IEEE Transactions on Biomedical Engineering. January 1970, 76-77. 